\title{
Androgen-deprivation therapy versus radical prostatectomy as monotherapy among clinically localized prostate cancer patients
}

This article was published in the following Dove Press journal:

OncoTargets and Therapy

15 June 2013

Number of times this article has been viewed

Jinan Liu'

Lizheng Shi ${ }^{2,3}$

Oliver Sartor ${ }^{3}$

Richard Culbertson ${ }^{2,3}$

'HealthCore, Wilmington, DE, USA; ${ }^{2} \mathrm{School}$ of Public Health and Tropical Medicine, Tulane University,

New Orleans, LA, USA; ${ }^{3}$ School of Medicine, Tulane University, New Orleans, LA, USA
Correspondence: Jinan Liu HealthCore, 800 Delaware Avenue 5th Floor, Wilmington, DE 1980I, USA

$\mathrm{Tel}+\mathrm{I} 3022302145$

Fax +I 3022302020

Email jliu@healthcore.com
Background: The most recent randomized controlled trial in a predominantly prostate-specific antigen-detected prostate cancer (PC) population found a nonsignificant reduction in mortality from radical prostatectomy (RP) compared to conservative management. The optimal treatment for clinically localized prostate cancer is anything but clear. The PC-specific mortality and allcause mortality were compared between primary androgen-deprivation treatment (PADT) and $\mathrm{RP}$, both as monotherapy, among clinically localized PC patients.

Methods: A retrospective cohort study among PC patients in Surveillance, Epidemiology and End Results-Medicare data with a median follow up of 2.87 years in the PADT cohort and 2.95 years in the RP cohort. Propensity score-matching was employed to adjust for the observed selection bias. PC-specific mortality and all-cause mortality were modeled using the Fine and Gray competing risk model and Cox proportional hazards model, respectively. The independent variables in these models included age, race, Gleason score risk groups, T-score, prostate-specific antigen, Charlson comorbidity, and index year of treatment initiation.

Results: After propensity score-matching, there were 1624 in the PADT cohort and 1624 in the RP cohort. All baseline values were comparable (all $P$-values $>0.35$ ). There were a total of 266 deaths (16.38\%) and 60 (3.69\%) PC-specific deaths among PADT recipients, while there were $56(3.45 \%)$ deaths and four $(0.25 \%)$ PC-specific deaths among RP recipients. According to the Kaplan-Meier estimation, the 8 -year survival rate was $43.39 \%$ in the PADT cohort and $79.62 \%$ in the RP cohort. PADT was associated with increased risk of overall mortality (hazard ratio $=2.98,95 \%$ confidence interval 2.35-3.79; $P<0.001)$ and increased risk of PC-specific mortality (hazard ratio $=12.47,95 \%$ confidence interval $4.48-34.70 ; P<0.001$ )

Conclusion: With adjustment for the observed selection bias, PADT was associated with increased all-cause mortality and PC-specific mortality when compared to RP.

Keywords: prostate cancer, primary androgen-deprivation treatment, radical prostatectomy, survival

\section{Introduction}

Prostate cancer (PC) is the most common malignancy among males, ${ }^{1}$ and accounts for $28 \%$ of incident cancer cases in men. In 2012, there were an estimated 241,740 new cases of PC, along with approximately 28,170 PC-induced deaths in the US. ${ }^{2}$ Based on data between 1999 and 2005, approximately 80\% of these new cases of PC were diagnosed at localized stages, ${ }^{3}$ with a 5 -year PC-specific survival rate approaching $100 \%$. Common treatments include radical prostatectomy (RP), active surveillance, radiation, and androgen-deprivation treatment (ADT). The National Comprehensive Cancer Network guidelines and European Association of Urology guidelines for 
management among clinically localized PC patients recommend all of these treatments except ADT as monotherapy. ${ }^{4,5}$

PC is a hormonally sensitive tumor, which usually responds to pharmacological manipulation of the androgen receptor. ADT serves as an important adjuvant strategy for the treatment of advanced $\mathrm{PC},{ }^{6-9}$ particularly for patients primarily treated with radiotherapy. However, no randomized controlled trials (RCTs) have evaluated ADT as monotherapy among clinically localized PC patients. Furthermore, large population-based studies observed inferior PC-specific survival and nonincreased overall survival following primary ADT (PADT) when compared to watchful waiting. ${ }^{10,11}$ Despite the lack of evidence of clinical benefits and recommendations, PADT has been commonly used among clinically localized patients. According to the Cancer of the Prostate Strategic Urologic Research Endeavor (CAPSURE) study, 14.4\% of clinically localized patients received PADT between 1990 and 2008. ${ }^{12}$

On the other hand, RP is a commonly recommended and used treatment for clinically localized PC patients, especially for those with a life expectancy of 10 years or more. Approximately 60,000 RP procedures are performed annually in the US. ${ }^{13}$ Its clinical benefit among early stage non-prostate-specific antigen (PSA)-detected PC patients has been demonstrated in the Scandinavian Prostate Cancer Group study 4 (SPCG-4). ${ }^{14}$ The most recent results in a predominantly PSA-detected population found a nonsignificant reduction in mortality from radical prostatectomy compared to conservative management. ${ }^{15}$ The optimal treatment for clinically localized PC is anything but clear.

To the best of our knowledge, there is no ongoing RCT to compare PADT to RP. Our previous retrospective analysis of the overall survival rates among veterans found that PADT was associated with threefold-higher overall mortality rate when compared to RP among localized PC patients. ${ }^{16}$ However, without important survival predictors, eg, the Gleason score, the findings in the Veterans Affairs study were not conclusive.

Knowledge of direct comparison between PADT and RP in terms of survival outcome is lacking in the literature and absolutely needed by patients and physicians. This study aimed to provide this kind of information to help these patients and their physicians to understand these two therapies better and thus to choose the appropriate one. We hypothesized that PADT was associated with higher PC-specific mortality and overall mortality.

\section{Methods}

\section{Data source}

The Surveillance, Epidemiology, and End Results (SEER)-Medicare dataset 1998-2007 was used in this study. The SEER program, funded by the National Cancer Institute, is an authoritative source of information on cancer incidence and survival in the US. SEER's 17 registries currently cover approximately $28 \%$ of the US population. This study was approved by the Tulane University Institutional Review Board. Informed consent was waived by the board, because the data did not contain personal identifiers.

\section{Study design}

The patients in the study needed to have at least have one diagnosis for PC (International Classification of Diseases [ICD]-9 diagnosis 185.xx). Other inclusion criteria were: (1) PC at the clinically localized stage (T1-T2, N0, M0); (2) no documented cancer diagnosis before PC diagnosis; (3) age 66-74 years in the year of diagnosis; (4) to at least have Medicare insurance coverage (parts A and B) 1 year before the time of the first diagnosis of $\mathrm{PC}$, to ensure that 1-year baseline information was available; and (5) either ADT or RP as monotherapy initiated within 180 days after the first diagnosis of PC.

The treatment initiation date was used as the index date. The individuals were followed from the index date until death, the end of data availability (December 31, 2007), or dropout from Medicare, whichever happened first. The year before the index-date data from Medicare was used to examine the baseline characteristics.

\section{Treatment definitions}

A categorical variable for therapies that consisted of mutually exclusive categories for the therapy received (RP surgery alone, ADT alone, conservative management, or others) were created using information from corresponding variables in the SEER-Medicare data set.

ADT was identified using a reported algorithm, ${ }^{17}$ including the Healthcare Common Procedure Coding System (HCPCS) codes for orchiectomy: 54520, 54521, 54522, 54530, 54535, or the ICD-9-CM code 62.4, and the HCPCS codes for luteinizing hormone-releasing hormone agonists: J1950, J9202, J9218, or J9219. RPs were identified using the HCPCS codes 55821, $55801,55810,55812,55815,55831,55840,55842,55845$, or ICD-9-CM codes 60.3, 60.4, 60.5, 60.6, and 60.62. ${ }^{18}$

\section{Data analysis}

The propensity score was assessed from the logistic model estimating the probability of receiving PADT versus RP for 
each patient. A PADT recipient was then matched to an RP recipient when their predicted probabilities were the closest, with a maximum distance tolerance of 0.005 in the propensity score. ${ }^{19}$ Propensity score-matching was expected to adjust for treatment-selection bias, which is a common bias in observational studies due to the lack of randomization. ${ }^{19}$ The covariates used for the propensity-matching analysis included patient characteristics (race, marital status, urban residence, regions), cancer status (PSA, T-score, Gleason score risk groups, diagnosis year), coexisting disease (Charlson comorbidity index [CCI], hypertension, diabetes), and healthcare utilization (hospitalization, surgery). We included these variables because we observed significant differences in these variables between these two cohorts, indicating these variables may impact treatment choice. PSA $\leq 10 \mathrm{ng} / \mathrm{mL}$ corresponds to low risk, PSA $11-20 \mathrm{ng} / \mathrm{mL}$ to median risk, and PSA $>20 \mathrm{ng} / \mathrm{mL}$ to high risk. ${ }^{20}$

After the matching, two cohorts with comparable baseline information were expected. Chi-squared tests for categorical variables and $t$-tests for continuous variables were used to verify if all the baseline characteristics were comparable. Overall survival rate was analyzed using the Kaplan-Meier method, and the hazard ratio (HR) was estimated using Cox proportional hazards $(\mathrm{PH})$ regression between propensity score-matched cohorts. The Fine and Gray competing risk model was used to model PC-specific survival. This method showed better performance than the standard Cox PH model when modeling competing risk survival among the elderly population. ${ }^{21}$

\section{Results}

Before propensity score-matching, there were 5804 patients in the PADT group and 5182 patients in the RP group. The baseline differences between these two groups were significant (Table 1). Patients in the RP cohort were more likely to be white, married, with a better Gleason score, and with a better overall health status (lower CCI, and fewer healthcare utilizations).

After propensity score-matching, there were 1624 in the PADT cohort and 1624 in the RP cohort. The average age in the PADT cohort was 70.25 (standard deviation 2.50 ) years, and was 70.21 (standard deviation 2.47 ) years in the RP cohort $(P=0.67)$. In Table 2 , all the baseline information was comparable (all $P$-values $>0.35$ ). In this matched sample, the majority were white, accounting for $81.59 \%$ in the PADT group and $81.77 \%$ in the RP cohort. The overall health status based on CCI and health-care utilizations was also comparable. The two groups had
Table I Baseline information between the PADT and RP cohorts before propensity score-matching

\begin{tabular}{|c|c|c|c|c|c|}
\hline & \multicolumn{2}{|c|}{ PADT } & \multicolumn{2}{|l|}{$\mathbf{R P}$} & \multirow[t]{2}{*}{$P$} \\
\hline & $\mathbf{n}$ & $\%$ & $\mathbf{n}$ & $\%$ & \\
\hline & 5804 & 100 & 5182 & 100 & \\
\hline Race & & & & & $<0.0001$ \\
\hline Not white & 1357 & 23.38 & $74 I$ & 14.30 & \\
\hline White & 4447 & 76.62 & $444 I$ & 85.70 & \\
\hline Married & & & & & $<0.0001$ \\
\hline No & 2064 & 35.56 & 896 & 17.29 & \\
\hline Yes & 3740 & 64.44 & 4286 & 82.71 & \\
\hline Urban residence & & & & & $<0.000$ I \\
\hline No & 708 & 12.20 & 480 & 9.26 & \\
\hline Yes & 5096 & 87.80 & 4702 & 90.74 & \\
\hline PSA & & & & & $<0.0001$ \\
\hline Low & 583 & 10.04 & 116 & 2.24 & \\
\hline Median & 2447 & 42.16 & 2378 & 45.89 & \\
\hline High & 1003 & 17.28 & 791 & 15.26 & \\
\hline Positive & 48 & 0.83 & $|5|$ & 2.91 & \\
\hline Unknown & 973 & 16.76 & 1423 & 27.46 & \\
\hline T-score & & & & & $<0.000$ I \\
\hline TI & 3318 & 57.17 & 768 & 14.82 & \\
\hline $\mathrm{T} 2$ & 2486 & 42.83 & 4414 & 85.18 & \\
\hline Gleason score risk group & & & & & $<0.000$ I \\
\hline $\begin{array}{l}\text { Moderately } \\
\text { differentiated }\end{array}$ & 2719 & 46.85 & 3193 & 61.62 & \\
\hline Poorly differentiated & 3085 & 53.15 & 1989 & 38.38 & \\
\hline Year at diagnosis & & & & & $<0.000$ I \\
\hline 1998 & 95 & 1.64 & 217 & 4.19 & \\
\hline 1999 & 95 & 1.64 & 202 & 3.90 & \\
\hline 2000 & 226 & 3.89 & 348 & 6.72 & \\
\hline 2001 & 223 & 3.84 & 424 & 8.18 & \\
\hline 2002 & 264 & 4.55 & 429 & 8.28 & \\
\hline 2003 & 437 & 7.53 & 330 & 6.37 & \\
\hline 2004 & 1352 & 23.29 & 1006 & 19.41 & \\
\hline 2005 & 1118 & 19.26 & 821 & 15.84 & \\
\hline 2006 & 1153 & 19.87 & 708 & 13.66 & \\
\hline 2007 & 841 & 14.49 & 697 & 13.45 & \\
\hline Region & & & & & $<0.000$ I \\
\hline North-central & 794 & 13.68 & 756 & 14.59 & \\
\hline Northeast & 1710 & 29.46 & 613 & 11.83 & \\
\hline South & 1336 & 23.02 & 919 & 17.73 & \\
\hline West & 1964 & 33.84 & 2894 & 55.85 & \\
\hline $\mathrm{CCl}$ group & & & & & $<0.0001$ \\
\hline 0 & 2329 & 40.13 & 3064 & 59.13 & \\
\hline$\leq 2$ & 2264 & 39.01 & 1693 & 32.67 & \\
\hline$>2$ & $121 \mid$ & 20.86 & 425 & 8.20 & \\
\hline Hypertension & & & & & $<0.000$ I \\
\hline No & 1057 & 18.21 & 1400 & 27.02 & \\
\hline Yes & 4747 & 81.79 & 3782 & 72.98 & \\
\hline Diabetes & & & & & $<0.000$ I \\
\hline No & 3474 & 59.86 & 3787 & 73.08 & \\
\hline Yes & 2330 & 40.14 & 1395 & 26.92 & \\
\hline Hospitalization & & & & & $<0.0001$ \\
\hline No & 4758 & 81.98 & 4715 & 90.99 & \\
\hline Yes & 1046 & 18.02 & 467 & 9.01 & \\
\hline Outpatient visit & & & & & 0.9922 \\
\hline No & $|58|$ & 27.24 & 1412 & 27.25 & \\
\hline Yes & 4223 & 72.76 & 3770 & 72.75 & \\
\hline
\end{tabular}

(Continued) 
Table I (Continued)

\begin{tabular}{|c|c|c|c|c|c|}
\hline & \multicolumn{2}{|c|}{ PADT } & \multicolumn{2}{|l|}{$\mathbf{R P}$} & \multirow[t]{2}{*}{$P$} \\
\hline & $n$ & $\%$ & $n$ & $\%$ & \\
\hline Surgery & & & & & $<0.0001$ \\
\hline No & 5046 & 86.94 & 4842 & 93.44 & \\
\hline Yes & 758 & 13.06 & 340 & 6.56 & \\
\hline
\end{tabular}

Abbreviations: PADT, primary androgen-deprivation treatment; RP, radical prostatectomy; PSA, prostate-specific antigen; $\mathrm{CCl}$, Charlson comorbidity index.

exactly the same number of patients in each index year and also at each PSA level. About $78.88 \%$ of PADT receipts were diagnosed at the T2 stage and $79.00 \%$ of RP receipts diagnosed at the $\mathrm{T} 2$ stage. In each group, about $50 \%$ of the patients had moderate/well-differentiated (Gleason score $2-7$ ) $\mathrm{PC}$ and $50 \%$ with poorly differentiated (Gleason score $8-10)$ cancer. $^{10}$

The median follow up was 2.87 years in the PADT group and 2.95 years in the RP group. There were a total of 266 deaths $(16.38 \%)$ in the PADT cohort and $56(3.45 \%)$ in the RP cohort (Figure 1, Kaplan-Meier curve, $P<0.05$ ). According to Kaplan-Meier estimates, the 3-year, 5-year, and 8 -year survival rate was $89.66 \%, 74.81 \%$, and $43.39 \%$ in the PADT cohort, respectively, and $96.06 \%, 92.08 \%, 79.62 \%$ in the RP cohort, respectively. In the Cox PH regression model (Table 3), PADT was associated with an increased risk of overall mortality $(\mathrm{HR}=2.98,95 \%$ confidence interval $[\mathrm{CI}]$ 2.35-3.79; $P<0.001)$.

Also in this Cox PH model, married patients were less likely to die (HR $=0.77,95 \%$ CI $0.61-0.97 ; P=0.026)$ than the unmarried patients. When compared to patients with a CCI score of zero, the patients with more comorbidities were more likely to die (HR $=1.66,95 \% \mathrm{CI}$ $1.27-2.17 ; P<0.001$ for patients in the $\mathrm{CCI} \leq 2$ group; and $\mathrm{HR}=2.21,95 \% \mathrm{CI} 1.51-3.22 ; P<0.001$ for patients in the CCI $>2$ group). Patients who had been previously hospitalized were also more likely to die ( $\mathrm{HR}=1.81,95 \%$ CI 1.17-2.80; $P=0.007)$.

There were 60 (3.69\%) PC-specific deaths in the PADT cohort and four $(0.25 \%)$ PC-specific deaths in the RP cohort. According to the Fine and Gray competing risk model (Figure 2 and Table 4), PADT was associated with increased risk of PC-specific mortality ( $\mathrm{HR}=12.47,95 \% \mathrm{CI}$ 4.48-34.70; $P<0.001)$.

Meanwhile, a worse Gleason score was associated with a higher likelihood of dying of PC (HR $=3.16,95 \%$ CI $1.77-5.64 ; P<0.001)$. Other independent variables were not significant after propensity score-matching (all $P$-values $>0.05)$.
Table 2 Baseline information between PADT and RP cohorts after propensity score-matching

\begin{tabular}{|c|c|c|c|c|c|}
\hline & \multicolumn{2}{|c|}{ PADT } & \multicolumn{2}{|l|}{$\mathbf{R P}$} & \multirow[t]{2}{*}{$P$} \\
\hline & $\mathbf{n}$ & $\%$ & $\mathbf{n}$ & $\%$ & \\
\hline & 1624 & 100 & 1624 & 100 & \\
\hline Race & & & & & 0.8898 \\
\hline Not white & 299 & $|8.4|$ & 296 & 18.23 & \\
\hline White & 1325 & 81.59 & 1328 & 81.77 & \\
\hline Married & & & & & 0.3691 \\
\hline No & 396 & 24.38 & 418 & 25.74 & \\
\hline Yes & 1228 & 75.62 & 1206 & 74.26 & \\
\hline Urban residence & & & & & 0.3640 \\
\hline No & 199 & 12.25 & 184 & 11.33 & \\
\hline Yes & 1425 & 87.75 & 1440 & 88.67 & \\
\hline PSA & & & & & 1.000 \\
\hline Low & 841 & 51.79 & 841 & 51.79 & \\
\hline Median & 126 & 7.76 & 126 & 7.76 & \\
\hline High & 53 & 3.26 & 53 & 3.26 & \\
\hline Positive & 372 & 22.91 & 372 & 22.91 & \\
\hline Unknown & 232 & 14.29 & 232 & 14.29 & \\
\hline T-score & & & & & 0.9306 \\
\hline TI & 343 & 21.12 & 341 & 21.00 & \\
\hline $\mathrm{T} 2$ & $|28|$ & 78.88 & 1283 & 79.00 & \\
\hline Gleason score risk group & & & & & 0.6740 \\
\hline Moderately/well differentiated & 814 & 50.12 & 826 & 50.86 & \\
\hline Poorly differentiated & 810 & 49.88 & 798 & 49.14 & \\
\hline Year at diagnosis & & & & & 1.000 \\
\hline 1998 & 26 & 1.60 & 26 & 1.60 & \\
\hline 1999 & 30 & 1.85 & 30 & 1.85 & \\
\hline 2000 & 85 & 5.23 & 85 & 5.23 & \\
\hline 2001 & 89 & 5.48 & 89 & 5.48 & \\
\hline 2002 & 97 & 5.97 & 97 & 5.97 & \\
\hline 2003 & 114 & 7.02 & 114 & 7.02 & \\
\hline 2004 & 369 & 22.72 & 369 & 22.72 & \\
\hline 2005 & 323 & 19.89 & 323 & 19.89 & \\
\hline 2006 & 279 & 17.18 & 279 & 17.18 & \\
\hline 2007 & 212 & 13.05 & 212 & 13.05 & \\
\hline Region & & & & & 0.9202 \\
\hline North-central & 247 & 15.21 & 235 & 14.47 & \\
\hline Northeast & 287 & 17.67 & 283 & 17.43 & \\
\hline South & 333 & 20.50 & 333 & 20.50 & \\
\hline West & 757 & 46.61 & 773 & 47.60 & \\
\hline $\mathrm{CCl}$ group & & & & & 0.5710 \\
\hline 0 & 833 & 51.29 & 803 & 49.45 & \\
\hline$\leq 2$ & 609 & 37.50 & 634 & 39.04 & \\
\hline$>2$ & 182 & 11.21 & 187 & $11.5 \mid$ & \\
\hline Hypertension & & & & & 0.4510 \\
\hline No & 390 & 24.01 & 383 & 23.58 & \\
\hline Yes & 1234 & 75.99 & $|24|$ & 76.42 & \\
\hline Diabetes & & & & & 0.7726 \\
\hline No & 1113 & 68.53 & 1093 & 67.30 & \\
\hline Yes & 511 & 31.47 & 531 & 32.70 & \\
\hline Hospitalization & & & & & 0.5831 \\
\hline No & | 444 & 88.92 & 1434 & 88.30 & \\
\hline Yes & 180 & 11.08 & 190 & 11.70 & \\
\hline Outpatient use & & & & & 0.5171 \\
\hline No & 436 & 26.85 & 452 & 27.83 & \\
\hline Yes & 1188 & 73.15 & 1172 & 72.17 & \\
\hline Surgery & & & & & 0.9491 \\
\hline No & 1496 & 92.12 & 1497 & 92.18 & \\
\hline Yes & 128 & 7.88 & 127 & 7.82 & \\
\hline
\end{tabular}

Abbreviations: PADT, primary androgen-deprivation treatment; RP, radical prostatectomy; PSA, prostate-specific antigen; CCl, Charlson comorbidity index. 


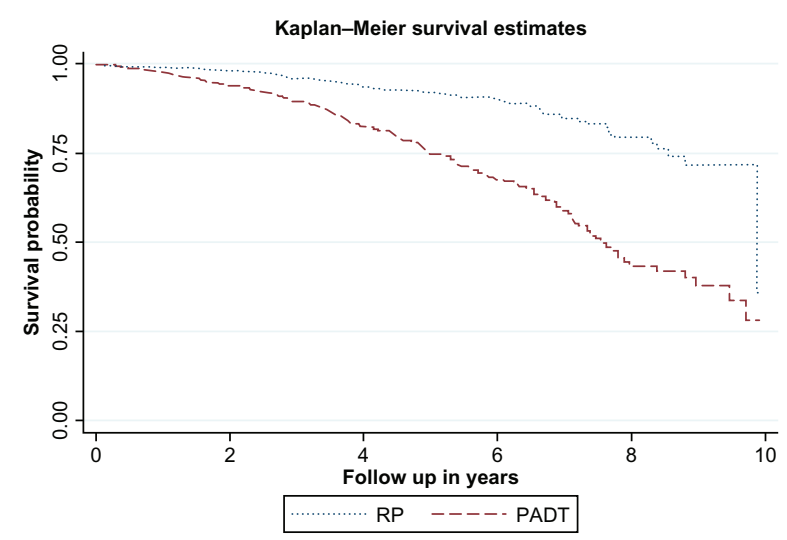

Figure I The Kaplan-Meier curve of overall survival between the primary androgen-deprivation treatment (PADT) and radical prostatectomy (RP) cohorts after propensity score-matching.

\section{Discussion}

This study documented the survival comparison between PADT and RP as monotherapy among clinically localized PC patients in terms of PC-specific mortality and overall mortality. One of the strengths of this study was that propensity score-matching was employed to ensure the cohorts had comparable baseline information. These baseline variables included the most important survival predictors, eg, the Gleason score groups, PSA, age, CCI, and the index year of treatment initiation. This strategy is powerful enough to adjust for observable selection bias, and has been commonly used to better draw causal inference from observational studies.

This study found that PADT was associated with a 12-fold higher PC-specific mortality rate than RP after controlling for the important survival predictors. Because PC-specific mortality was a primary outcome in many PC clinical trials, this comparison between PADT and RP in terms of PC-specific mortality from this study can be related to the outcomes from clinical trials and also from real-world observational studies. So far, there is no evidence of any clinical benefits of PADT for localized PC patients in the literature. On the other hand, treatment with RP was associated with a significantly lower risk of disease-specific mortality and overall mortality according to the SPCG-4..$^{22}$ Meanwhile RP has provided good long-term clinical outcomes for patients with high-risk localized PC and avoided the use of ADT in approximately $70 \%$ of these patients. ${ }^{23} \mathrm{RP}$ (with adjuvant hormonal therapy) provided improved local control in patients with lymph node-positive PC. ${ }^{24}$ However, the Prostate Cancer Intervention Versus Observation Trial found that when compared to observation, RP produced reductions in allcause and PC mortality rates, but the difference was not
Table 3 Cox proportional hazards regression on overall survival between the PADT and RP cohorts after propensity scorematching

\begin{tabular}{|c|c|c|c|c|}
\hline & HR & $\begin{array}{l}\text { Lower } \\
95 \% \mathrm{Cl}\end{array}$ & $\begin{array}{l}\text { Higher } \\
95 \% \mathrm{Cl}\end{array}$ & $P$ \\
\hline PADT & 2.98 & 2.35 & 3.79 & $<0.001$ \\
\hline Age at diagnosis & 1.03 & 0.99 & 1.08 & 0.154 \\
\hline White & 0.80 & 0.62 & 1.02 & 0.073 \\
\hline Married & 0.77 & 0.61 & 0.97 & 0.026 \\
\hline Urban & 0.74 & 0.54 & 1.02 & 0.065 \\
\hline \multicolumn{5}{|l|}{ Region } \\
\hline Northeast & 1.14 & 0.75 & 1.74 & 0.548 \\
\hline South & 1.19 & 0.82 & I.7I & 0.359 \\
\hline West & 1.17 & 0.84 & 1.63 & 0.354 \\
\hline \multicolumn{5}{|l|}{ PSA } \\
\hline Low & 0.76 & 0.43 & 1.33 & 0.339 \\
\hline Median & 1.20 & 0.61 & 2.36 & 0.606 \\
\hline High & 1.30 & 0.59 & 2.86 & 0.516 \\
\hline Unknown & 1.30 & 0.89 & 1.89 & 0.179 \\
\hline $\mathrm{T} 2$ & 1.33 & 1.00 & 1.76 & 0.046 \\
\hline Worse Gleason score & 1.29 & 1.02 & 1.62 & 0.032 \\
\hline \multicolumn{5}{|l|}{$\mathrm{CCl}$} \\
\hline$\leq 2$ & 1.66 & 1.27 & 2.17 & $<0.001$ \\
\hline$>2$ & 2.21 & 1.51 & 3.22 & $<0.001$ \\
\hline Diabetes (yes) & 0.98 & 0.76 & 1.26 & 0.886 \\
\hline CVD history & 1.14 & 0.98 & 1.31 & 0.088 \\
\hline \multicolumn{5}{|l|}{ Year at diagnosis } \\
\hline 1998 & 0.01 & 0.01 & 0.03 & $<0.001$ \\
\hline 1999 & 0.03 & 0.01 & 0.09 & $<0.001$ \\
\hline 2000 & 0.03 & 0.01 & 0.08 & $<0.001$ \\
\hline 2001 & 0.07 & 0.03 & 0.17 & $<0.001$ \\
\hline 2002 & 0.09 & 0.04 & 0.22 & $<0.001$ \\
\hline 2003 & 0.11 & 0.05 & 0.27 & $<0.001$ \\
\hline 2004 & 0.08 & 0.04 & 0.17 & $<0.001$ \\
\hline 2005 & 0.16 & 0.08 & 0.32 & $<0.001$ \\
\hline 2006 & 0.30 & 0.15 & 0.59 & 0.001 \\
\hline Hospitalization (yes) & 1.81 & 1.17 & 2.80 & 0.007 \\
\hline Surgery (yes) & 0.86 & 0.53 & 1.39 & 0.531 \\
\hline Outpatient use (yes) & 1.18 & 0.90 & 1.54 & 0.223 \\
\hline Hypertension (yes) & 1.12 & 0.85 & 1.48 & 0.420 \\
\hline
\end{tabular}

Abbreviations: PADT, primary androgen-deprivation treatment; RP, radical prostatectomy; HR, hazard ratio; $\mathrm{Cl}$, confidence interval; PSA, prostate-specific antigen; $\mathrm{CCl}$, Charlson comorbidity index; CVD, cardiovascular disease.

significant except in certain subsets, and less than $3 \%$ in absolute terms over 12 years. ${ }^{15}$ It is still premature to label RP as the gold standard for clinically localized PC, but RP displayed obvious dominance over ADT as a monotherapy among these patients in this study.

Patients with a worse Gleason score had an increased PC-specific mortality in this study. This finding was not a surprise. In the literature, a Gleason score of 7 or greater indicated the probability of a $29 \%$ chance of dying of PC, and the corresponding value for a Gleason score of 8 or greater was $48 \%$, based on a 20 -year follow-up of a population-based 


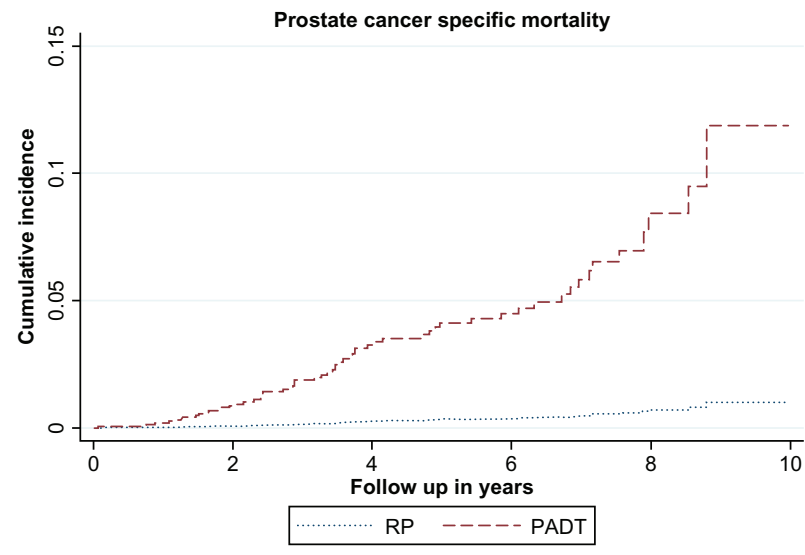

Figure 2 The cumulative incidence curve of prostate cancer-specific mortality between the primary androgen-deprivation treatment (PADT) and radical prostatectomy (RP) cohorts after propensity score-matching.

non-PSA detected cohort in Sweden. ${ }^{25}$ This makes the Gleason score one of the most important survival predictors among PC patients.

Also, PADT was associated with a threefold-higher risk of overall mortality. This is confirmation of our earlier finding that PADT was associated with a threefold increase in overall mortality rate after a median follow up of 4.3 years when compared to RP. ${ }^{16}$ Although propensity score-matching was also employed to make sure that the baseline characteristics were comparable in the VA study, the Gleason score was not available. The Gleason score risk group was available in the SEER-Medicare data. One possible reason for the increased overall mortality rate associated with PADT is that ADT for PC could induce metabolic syndrome, which may contribute to noncancer-related (predominantly cardiovascular) morbidity and mortality. ${ }^{26}$

In this matched sample, patients with more comorbidities (CCI) had an increased overall mortality rate. Previous findings revealed that $\mathrm{CCI}$ was a strong predictor of survival among localized PC patients. ${ }^{27}$ It is known that the majority of PC patients die with PC rather than of PC. This has been confirmed in this study, where the likelihood of death from competing causes exceeded the risk of death from PC. This makes comorbidity management for PC extremely important. Also, married patients had reduced overall mortality. Married patients were more likely to get family support and better family care. This could be the reason married people survived longer in this study. Lastly, people with a previous use of hospitalization were more likely to die. Previous hospitalization was an indicator of worse overall health status, which might result in shorter survival.
Table 4 Competing risk analysis of prostate cancer-specific survival between the PADT and RP cohorts after propensity score-matching

\begin{tabular}{|c|c|c|c|c|}
\hline & HR & $\begin{array}{l}\text { Lower } \\
95 \% \mathrm{Cl}\end{array}$ & $\begin{array}{l}\text { Higher } \\
95 \% \mathrm{Cl}\end{array}$ & $P$ \\
\hline PADT & 12.47 & 4.48 & 34.7 & $<0.001$ \\
\hline Age at diagnosis & 0.96 & 0.86 & 1.07 & 0.45 \\
\hline White & 0.94 & 0.49 & 1.82 & 0.86 \\
\hline Married & 0.86 & 0.48 & 1.51 & 0.59 \\
\hline \multicolumn{5}{|l|}{ Region } \\
\hline Northeast & 1.59 & 0.58 & 4.38 & 0.37 \\
\hline South & 1.08 & 0.43 & 2.71 & 0.86 \\
\hline West & 1.27 & 0.58 & 2.76 & 0.55 \\
\hline Urban & 0.53 & 0.28 & 1.00 & 0.05 \\
\hline \multicolumn{5}{|l|}{ PSA } \\
\hline Positive & 2.68 & 0.58 & 12.27 & 0.21 \\
\hline Median & 2.43 & 0.71 & 8.38 & 0.16 \\
\hline High & 1.23 & 0.15 & 9.96 & 0.84 \\
\hline Unknown & 2.43 & 0.79 & 7.49 & 0.12 \\
\hline $\mathrm{T} 2$ & I.71 & 0.86 & 3.42 & 0.13 \\
\hline Worse Gleason score & 3.16 & 1.77 & 5.64 & $<0.001$ \\
\hline \multicolumn{5}{|l|}{ Year at diagnosis } \\
\hline 1998 & 0.40 & 0.04 & 4.47 & 0.46 \\
\hline 1999 & 0.45 & 0.05 & 4.50 & 0.50 \\
\hline 2000 & 0.43 & 0.05 & 3.68 & 0.45 \\
\hline 2001 & 0.40 & 0.04 & 3.65 & $0.4 I$ \\
\hline 2002 & 0.67 & 0.08 & 5.27 & 0.70 \\
\hline 2003 & 0.29 & 0.03 & 2.46 & 0.25 \\
\hline 2004 & 0.24 & 0.05 & 1.13 & 0.07 \\
\hline 2005 & 0.31 & 0.06 & 1.58 & 0.16 \\
\hline 2006 & 0.37 & 0.06 & 2.45 & 0.31 \\
\hline $\mathrm{CCl} \leq 2$ & 0.82 & 0.40 & 1.68 & 0.59 \\
\hline $\mathrm{CCl}>2$ & 1.12 & 0.35 & 3.65 & 0.85 \\
\hline Hospitalization (yes) & 1.89 & 0.80 & 4.46 & 0.14 \\
\hline Surgery (yes) & 1.02 & 0.33 & 3.15 & 0.97 \\
\hline Outpatient use (yes) & 1.58 & 0.81 & 3.07 & 0.18 \\
\hline Hypertension (yes) & 1.01 & 0.55 & 1.83 & 0.98 \\
\hline Diabetes (yes) & 0.96 & 0.46 & 2.02 & 0.92 \\
\hline CVD history & 0.86 & 0.55 & 1.34 & 0.49 \\
\hline
\end{tabular}

Abbreviations: PADT, primary androgen-deprivation treatment; RP, radical prostatectomy; HR, hazard ratio; $\mathrm{Cl}$, confidence interval; PSA, prostate-specific antigen; $\mathrm{CCl}$, Charlson comorbidity index; CVD, cardiovascular disease.

This was an observational study rather than an RCT. First, although propensity score-matching was employed to balance the baseline characteristics, selection bias may still be an issue due to unobserved variables, eg, patient's income information and provider's characteristics. However, the most important survival predictors in the literature, eg, the Gleason score risk group, PSA, CCI, and age, were comparable after matching. Second, this study merely focused on survival outcomes and did not assess the side effects and quality of life between these two cohorts. Third, people in this study were aged 66 years or older. This was a highly selective population, and could be one of the reasons 
we observed different survival results from what has been reported in PIVOT study. ${ }^{13}$ Caution should be exercised in generalizing findings from this study to other populations. Despite these limitations, this was the first study that aimed to explore the comparison in terms of PC-specific mortality and overall mortality between PADT and RP among localized PC patients. Its findings have significant clinical implications and contribute to the literature on survival comparison among treatment options for localized PC patients. The highly selective population could also be one of the reasons we observed different treatment patterns among these patients when compared to patients in the CAPSURE registry. ${ }^{12}$ Caution should be exercised in generalizing findings from this study to other populations.

In summary, PADT was associated with increased overall mortality and PC-specific mortality when compared to RP. The difference in PC-specific mortality is mostly attributable to the depression of cancer progress associated with $\mathrm{RP}$, while the difference in overall survival is likely due to increased metabolic syndrome associated with PADT. All these findings support the conclusion that ADT as a monotherapy may not be an appropriate therapeutic choice for the clinically localized PC population. Patients should be well informed by their doctors about this before they make treatment selections together.

\section{Acknowledgments}

The authors would like to thank the SEER program for providing this cancer data. No funding was received for this study.

\section{Disclosure}

The authors declare there are no competing financial interests in relation to the work described. Some of the findings in this paper were presented at the 2012 17th Annual International ISPOR meeting and covered in a media report by Renal and Urology News in June 2012.

\section{References}

1. Klein EA, Thompson IM. Update on chemoprevention of prostate cancer. Curr Opin Urol. 2004;14:143-149.

2. American Cancer Society. Cancer Facts and Figures 2012. Atlanta: American Cancer Society; 2012.

3. Jemal A, Siegel R, Xu J, Ward E. Cancer statistics, 2010. CA Cancer J Clin. 2010;60:277-300.

4. Mohler J, Bahnson RR, Boston B, et al. NCCN clinical practice guidelines in oncology: prostate cancer. J Natl Compr Canc Netw. 2010;8: 162-200.

5. Mottet N, Bellmunt J, Bolla M, et al. EAU guidelines on prostate cancer. Part II: treatment of advanced, relapsing, and castration-resistant prostate cancer. Eur Urol. 2011;59:572-583.
6. Messing EM, Manola J, Sarosdy M, Wilding G, Crawford ED, Trump D Immediate hormonal therapy compared with observation after radical prostatectomy and pelvic lymphadenectomy in men with node-positive prostate cancer. N Engl J Med. 1999;341:1781-1788.

7. Bolla M, Gonzalez D, Warde P, et al. Improved survival in patients with locally advanced prostate cancer treated with radiotherapy and goserelin. N Engl J Med. 1997;337:295-300.

8. Bolla M, Van Tienhoven G, Warde P, et al. External irradiation with or without long-term androgen suppression for prostate cancer with high metastatic risk: 10-year results of an EORTC randomised study. Lancet Oncol. 2010;11:1066-1073.

9. Widmark A, Klepp O, Solberg A, et al. Endocrine treatment, with or without radiotherapy, in locally advanced prostate cancer (SPCG-7/ SFUO-3): an open randomised phase III trial. Lancet. 2009;373: 301-308.

10. Lu-Yao GL, Albertsen PC, Moore DF, et al. Survival following primary androgen deprivation therapy among men with localized prostate cancer. JAMA. 2008;300:173-181.

11. Wong YN, Freedland SJ, Egleston B, Vapiwala N, Uzzo R, Armstrong K. The role of primary androgen deprivation therapy in localized prostate cancer. Eur Urol. 2009;56:609-616.

12. Cooperberg MR, Broering JM, Carroll PR. Time trends and local variation in primary treatment of localized prostate cancer. J Clin Oncol. 2010;28:1117-1123.

13. Wilt TJ, Brawer MK, Barry MJ, et al. The Prostate Cancer Intervention Versus Observation Trial: VA/NCI/AHRQ Cooperative Studies Program \#407 (PIVOT): design and baseline results of a randomized controlled trial comparing radical prostatectomy to watchful waiting for men with clinically localized prostate cancer. Contemp Clin Trials. 2009;30:81-87.

14. Bill-Axelson A, Holmberg L, Filén F, et al. Radical prostatectomy versus watchful waiting in localized prostate cancer: the Scandinavian prostate cancer group-4 randomized trial. J Natl Cancer Inst. 2008;100: 1144-1154.

15. Wilt TJ. Prostate cancer intervention versus observation trial: main results from randomized trial comparing radical prostatectomy to watchful waiting in men with clinically localized prostate cancer. American Urological Association Annual Meeting; May 14-19, 2011; Washington, USA.

16. Liu J, Shi L, Sartor O. Monotherapy of androgen deprivation therapy versus radical prostatectomy among veterans with localized prostate cancer: a comparative effectiveness analysis of retrospective cohorts. J Comp Eff Res. 2012;2:21-27.

17. Shahinian VB, Kuo YF, Freeman JL, Goodwin JS. Risk of fracture after androgen deprivation for prostate cancer. N Engl J Med. 2005;352: 154-164.

18. Wong YN, Freedland S, Egleston B, Hudes G, Schwartz JS, Armstrong K. Role of androgen deprivation therapy for node-positive prostate cancer J Clin Oncol. 2009;27:100-105.

19. Caliendo M, Kopeinig S. Some practical guidance for the implementation of propensity score matching. J Econ Surv. 2008;22:31-72.

20. Thompson I, Thrasher JB, Aus G, et al. Guideline for the management of clinically localized prostate cancer: 2007 update. J Urol. 2007;177: 2106-2131.

21. Wolbers M, Koller MT, Witteman JC, Steyerberg EW. Prognostic models with competing risks: methods and application to coronary risk prediction. Epidemiology. 2009;20:555-561.

22. Bill-Axelson A, Holmberg L, Ruutu M, et al. Radical prostatectomy versus watchful waiting in early prostate cancer. N Engl J Med. 2005;352: 1977-1984.

23. Miocinovic R, Berglund RK, Stephenson AJ, et al. Avoiding androgen deprivation therapy in men with high-risk prostate cancer: the role of radical prostatectomy as initial treatment. Urology. 2011;77:946-950.

24. Wiegand LR, Hernandez M, Pisters LL, Spiess PE. Surgical management of lymph-node-positive prostate cancer: improves symptomatic control. BJU Int. 2011;107:1238-1242. 
25. Andrén O, Fall K, Franzén L, Andersson SO, Johansson JE, Rubin MA. How well does the Gleason score predict prostate cancer death? A 20-year follow-up of a population based cohort in Sweden. J Urol. 2006;175:1337-1340.

26. Clements A, Gao B, Yeap SH, Wong MK, Ali SS, Gurney H. Metformin in prostate cancer: two for the price of one. Ann Oncol. 2011;22: 2556-2560.
27. Kastner C, Armitage J, Kimble A, Rawal J, Carter PG, Venn S. The Charlson comorbidity score: a superior comorbidity assessment tool for the prostate cancer multidisciplinary meeting. Prostate Cancer Prostatic Dis. 2006;9:270-274.

\section{Publish your work in this journal}

OncoTargets and Therapy is an international, peer-reviewed, open access journal focusing on the pathological basis of all cancers, potential targets for therapy and treatment protocols employed to improve the management of cancer patients. The journal also focuses on the impact of management programs and new therapeutic agents and protocols on

\section{Dovepress}

patient perspectives such as quality of life, adherence and satisfaction. The manuscript management system is completely online and includes a very quick and fair peer-review system, which is all easy to use. Visit http://www.dovepress.com/testimonials.php to read real quotes from published authors.

\footnotetext{
Submit your manuscript here: http://www.dovepress.com/oncotargets-and-therapy-journal
} 